\title{
THE IMPACT OF PROJECT CITIZENSHIP BEHAVIOURS, PROJECT COMMITMENT AND LEARNING PROJECT ORGANIZATION ON THE SUCCESS OF THE PROJECT: A MODEL PROPOSAL
}

\author{
DOI: 10.17261/Pressacademia.2018.988 \\ JMML- V.5-ISS.4-2018(3)-p.275-285
}

Zeyd Gulesin ${ }^{1}$, Yonca Gurol ${ }^{2}$

${ }^{1}$ Yıldız Teknik Üniversitesi, Sosyal Bilimler Enstitüsü, İşletme Yönetimi Anabilim Dalı, Davutpaşa Kampüsü, 34349, Esenler, Istanbul, Turkey. zeyd@gulesin.com,ORCID: 0000-0002-0939-9623

${ }^{2}$ Yıldız Teknik Üniversitesi, Sosyal Bilimler Enstitüsü, İşletme Yönetimi Anabilim Dalı, Davutpaşa Kampüsü, 34349, Esenler, Istanbul, Turkey. gurol@yildiz.edu.tr, ORCID: 0000-0002-0618-5750

Date Received: September 3, 2018

Date Accepted: December 7, 2018

To cite this document

Gulesin, Z., Gurol, Y. (2018). The impact of project citizenship behaviours, project commitment and learning project organization on the success of the project: a model proposal. Journal of Management, Marketing and Logistics (JMML), V.5(4), p.275-285.

Permemant link to this document: http://doi.org/10.17261/Pressacademia.2018.988

Copyright: Published by PressAcademia and limited licenced re-use rights only.

\section{ABSTRACT}

Purpose - This study examines the concepts of organizational commitment, organizational citizenship behaviors and learning organization characteristics from a project organization point of view; aims to explain how the behaviors and characteristics in this context would affect achieving the objectives of the project. Based on these results it is also aimed to create a model that would maximize success in project management.

Methodology - A broad literature survey has been conducted on the organizational citizenship behavior, learning organizations and organizational commitment concepts from project management point of view. The results of researches that are directly related to the topic have been put together. At the last stage, research findings were synthesized and a model is developed based on the dimensions that positively influence success in the project management.

Findings- In addition to knowing and implementing the right tools and techniques, it has become clear that the presence of human factors such as stakeholders' commitment to the project, learning organization, and project citizenship behaviors also play a very important role in achieving the goals of the project successfully.

Conclusion- Recently, practitioners focus more on the tools and techniques used in the project management and the competencies of the team. But the human factors in project management remain neglected. This study draws attention to the shortcomings of these elements, which have been overlooked in traditional project management approaches, which are currently being implemented intensively. Drawing attention to these elements through this study, a model is developed which could be beneficial for the academicians as well as professional project managers.

Keywords: Project management, project commitment, project citizenship, learning project organization, successful project management. JEL Codes: M16, F23, M14

PROJE VATANDAŞLIĞI DAVRANIŞLARI, PROJEYE BAĞLILIK VE ÖĞRENEN PROJE ORGANIZASYONUNUN PROJENIN BAŞARISINA ETKISI: BIR MODEL ÖNERISI

\section{ÖZET}

Amaç- Bu çalışma örgütsel bağıııı, örgütsel vatandaşlık ve öğrenen organizasyon karakteristikleri kavramlarını proje organizasyonu bakış açısından inceleyerek; bu kapsamdaki davranış ve karakteristiklerin proje yönetiminde hayat bulması durumunda projenin başarısını nasıl etkileyeceğinin açıklanmasını ve bu sonuçlara dayanarak proje yönetiminde başarıyı maksimize edecek bir model ortaya konulmasını amaçlamaktadır.

Yöntem- Proje yönetimi açısından örtügsel vatandaşlık, öğrenen organizasyonlar ve örgütsel bağılık kavramları üzerine geniş bir literatur araştırması yapılarak konu ile ilgili doğrudan ilişkili olan araştırmaların sonuçları bir araya getirilmiştir. Son aşamada ise araştırma bulguları sentezlenerek proje yönetiminde başarıyı pozitif etkileyen boyutlar üzerinden bir model önerisi yapılmıştır.

Bulgular- Projelerin hedeflerine başarı ile ulaşmasında, doğru araçları ve teknikleri bilip etkin uygulamanın yanında paydaşların projeye ve proje organizasyonuna olan bağ|ııkları, öğrenen organizasyon olabilmesi ve proje vatandaşlığı davranışları gibi insani unsurların varlığının da çok önemli rol oynadığı ortaya çıkmıştır.

Sonuç- Son dönemlerde araç ve teknikler, proje ekibi üyelerinin teknik yetkinlikleri üzerine yoğunlaşılmakta, proje yönetiminde insani unsurlar ikinci planda kalmaktadır. Bu çalışma ile günümüzde yoğun olarak uygulanmakta olan geleneksel proje yönetim yaklaşımların gözardı edilen bu unsurlara ilişkin eksikliklere dikkat çekilmiştir. Geliştirilen model hem hem bu alanda çalışma yapan akademisyenlerin ve hem de profesyonel proje yöneticilerinin istifadesine sunulmuştur.

Anahtar Kelimeler: Proje yönetimi, proje bağlılı̆ı, proje vatandaşlığı, öğrenen proje organizasyonu, proje yönetiminde başarı. JEL Kodları: M16, F23, M14 


\section{GíRiş}

Proje yönetimi; bilgi, beceri, araç ve tekniklerin, projenin gereksinimlerini yerine getirmek amacıyla proje aktivitelerine uygulanmasıdır (Project Management Institute 2013). Geleneksel olarak; altın üçgen diye adlandırılan; zamanında, planlanan bütçe içerisinde ve belirlenmiş kalite kriterlerine uygun olarak tamamlanan projeler başarılı olarak görülmektedir (Project Management Institute 2013; Baccarini 1999; Westerveld 2003). Proje yönetimi bilgi birikimi, proje süresince yürütülmesi gereken aktiviteleri standartlaştırarak organizasyonların yeni ürünler ve hizmetler ortaya çıkarabilmelerini kolaylaştırmaktadır. Proje yönetimini temelde standartlaştırılmış aktivitelerin yürütülmesi, belirli araç ve tekniklerin uygulanması olarak gören ve günümüzde de genel kabul gören geleneksel bakış Taylorizmden beslenmektedir. Frederick Taylor 1911 yılında yayımladığı "Bilimsel Yönetimin IIlkeleri" adlı eserinde çalışanları makinelerin uzantıları olarak değerlendirmektedir ve iş görenlerin performansını artırmak için benimsenmesi gereken temel ilkeleri sıralamaktadır. Özetle verimliliği artırmak için; yapılan işler sürekli kontrol edilmeli, her iş için standart yöntem ve zaman belirlenmeli, verilecek eğitimler sayesinde çalışanları uzmanlaşmaları ve bu sayede işlerini en iyi şekilde yapmaları sağlanmalıdır (Güney 2011). Organizasyon belirli amaçlara ulaşmak amacıyla rasyonel esaslara göre dizayn edilen bir makinedir (Leblebici 2008). Rasyonel birey; duygu ve değer yargılarından uzaklaşmış olarak, örgütün tasarlanabilen, şekil verilebilen bir parçası haline gelmelidir (Keskin 2016).

Ancak klasik yönetim yaklaşımında göz ardı edilen insan unsuruna Barnard ve Selznick tarafından dikkat çekmiştir: Zira örgütler sadece kontrol mekanizmalarının uygulandığı biçimsel yapılardan değil sosyal ilişkilere dayanan ve kendiliğinden gelişen informel yapılardan oluşur (Selznick 1948; Barnard 1938). Örgütlerin performansı standartlaşmış aktivitelerin yürütülmesi ve bürokratik kontrollerin uygulanmasından ziyade üyelerin uygun duygu ve tutumlara sahip olduğu, iletişim ve etkileşimin güçlü olduğu sosyal bir yapı ile mümkündür. Günümüzde sürekli değişmeye meyilli olan gereksinimlerin yönetilmesi, projenin hedeflerine ulaşabilmesi için proje ekibinin intiyaç duyduğu koçluk ve mentorlüğün verilmesi, karşılaşılan sorunların çözümü için ekip içerisinde pratik ve eleştirel düşüncenin öne çıkarılması, risklerin belirlenerek soruna dönüşmeden aksiyon alınabilmesi için paydaşlar arasında etkili iletişimin sağlanması gibi informel/sosyal yapıya ilişkin yetkinlikler hiç şüphesiz ki projenin başarısı için en az teknik uzmanlıklar kadar gerekli ve önemlidir (Gülesin 2016; Zinn 2007). Sağlıklı iletişimin temin edilmesi, global iş çevresindeki belirsizlikler, kültürlerarası yetkinlik yönetimi, hukuki ve politik çeşitlilikler, global takım oluşturabilme ve geliştirme, yerel çalışma koşullarındaki farklılıklar, ekip üyelerindeki farklı dini inanışlar gibi proje yönetiminde karşılaşılan güçlüklerle (Gülesin 2015) baş edebilecek adaptif yaklaşımları geliştirme ve başarıyla projeyi tamamlayabilmek için proje paydaşları arasında iletişim ve etkileşimin azami seviyede olması gerekmektedir. Bu durumda proje ekibinin "rol dışı davranış" performansı önem kazanmaktadır.

Çalışmanın ikinci bölümünde projenin başarısı kavramına ve rol dışı davranışların önemine değinilmektedir. Ardından örgüt içerisindeki temel rol dışı davranışlardan olan "örgütsel vatandaşlık", "örgütsel bağlılık" ve "öğrenen organizasyon" kavramlarından hareketle proje organizasyonundaki temel rol dışı davranışları olan "proje vatandaşlığı" ve "projeye bağlılık" kavramlarına varılmakta ve "öğrenen proje organizasyonu" karakteristikleri ile projenin başarısındaki rolü incelenmektedir. Bu kavramlardan ve projenin başarısındaki hareketle önerilen model altıncı bölümde detaylandırılmıştır.

\section{PROJENIN BAŞARISI, PROJEDE ROL IÇi VE ROL DIŞI DAVRANIŞLARIN ÖNEMI}

Proje yönetiminin organizasyonlarda stratejik bir yönetim aracı haline gelmesi ve öneminin giderek artması, insan unsurunun başarıdaki rolünü ortaya çıkaran araştırmaların yapılmasına paralel olarak projenin başarısının ölçülmesine yönelik farklı tanımlar ortaya çıkmıştır. Buna göre projenin başarısı sadece teknik gereksinimlerin karşılanması ve misyonun yerine getirilmesi ile değil; aynı zamanda anahtar proje paydaşlarının yüksek seviyede memnuniyetinin de sağlanmış olması ile mümkündür (Baker 1983). Başarının ölçülmesinde altın üçgeninin yeterli olmadığı; davranışsal faktörlerin, amacın net olmasının, üst yönetim desteğinin ve paydaşlar arası ilişki ve iletişim kalitesinin de önemli olduğu sonucunu çıkaran araştırmalar yapılmıştır (Pinto 1990). Atkinson geliştirdiği "The square route" adlı modelinde bütçe, zaman ve kalite üçlemesinin yanında başarı kriterlerine üç bileşen daha eklemiştir: geliştirilen bilgi sistemi, organizasyona sağlanan fayda (organizasyonel öğrenme, verimlilik, etkililik ve karlılık gibi), paydaşlara sağlanan fayda (kullanıcı memnuniyeti, çevresel etki, kişisel gelişim ve profesyonel öğrenme gibi) (Atkinson 1999). Turner projenin başarısının ölçümünde sadece altın üçgene odaklanmanın yanlış olduğunu, aksine tek önemli göstergenin proje paydaşlarının projenin başlangıcında üzerinde uzlaştığı başarı kriterleri olduğunu ifade etmektedir (Turner 1999). Tablo 1 'de literatürdeki bazı akademik çalışmaların projelerin başarı kriterlerine ilişkin elde ettikleri sonuçları verilmektedir.

Tablo 1: Projenin Başarı Kriterlerine İlişkin Bazı Araştırmalar

\begin{tabular}{ll}
\hline Referans & Projenin Başarı Kriterleri \\
\hline Baker (1983) & Anahtar proje paydaşlarının yüksek seviyede memnuniyeti \\
\hline Pinto (1990) & Paydaşlar arası ilişki, iletişim kalitesi, davranışsal faktörler \\
\hline Atkinson (1999) & Organizasyona sağlanan fayda, Geliştirilen bilgi sistemi, paydaşlara sağlanan fayda \\
\hline
\end{tabular}




\begin{tabular}{ll}
\hline Turner (1999) & Paydaşların başlangıçta belirlediği başarı kriterleri \\
\hline Ika (2015) & $\begin{array}{l}\text { Organizasyona sağlanan fayda, Son kullanıcı memnuniyeti, Paydaşlara sağlanan fayda, Proje } \\
\text { ekibine sağlanan fayda, Organizasyonun stratejik hedeflerine sağlanan fayda. }\end{array}$ \\
\hline Khang ve Moe (2008) & $\begin{array}{l}\text { Projenin hedef grubun önceliklerine uyumu, Projenin önceden belirlenen hedeflerine } \\
\text { ulaşması, Projenin ortaya çıkardığı planlı vey aplansız olumlu veya olumsuz etkiler }\end{array}$ \\
\hline Kerzner (1998) & $\begin{array}{l}\text { Zaman, Bütçe, İstenilen kalite seviyesine ulaşma, Müşteri tarafından kabul edilmesi, } \\
\text { Müşterinin referans olarak gösterilmesine izin vermesi }\end{array}$ \\
\hline
\end{tabular}

Dolayısıyla projenin performansı; Taylor'un klasik yönetim anlayışından beslenen ve altın üçgenin işaret ettiği projenin temel çıktılarını üreten davranışların yanında; Barnard'ın dile getirdiği, proje organizasyonu içindeki tanımlı rol ve sorumluluklarda yer almayan ancak başarıda etkili olan motivasyon, istek ve gönüllülük esasına dayalı davranışlar ile de ilgilidir. Söz konusu iki ayrı performans Organ tarafından rol içi ve rol dışı davranışlar olarak kategorize edilmiştir: Rol içi davranışlar, iş görenlerin görev tanımlarında açık olarak belirtilen ve buna istinaden kendilerinden yerine getirmeleri beklenilen sorumluluklar iken; rol dışı davranışlar ise gönüllülük esasına dayanan, çalışanın görev tanımında yer almayan ve organizasyonun ödül sisteminde tanımlanmamış olan davranışlardır (Organ 1988; Netemeyer 2007). Hem rol içi davranışlar hem de rol dışı davranışlar proje organizasyonunun verimli çalışabilmesi için ve projenin başarısı için kritik önemi haizdir. (Drago 1998).

\section{PROJE VATANDAŞLIĞI DAVRANIŞLARI}

Rol dışı davranışlar bağlamındaki anahtar kavramlardan birisi “Örgütsel Vatandaşlık Davranışı (ÖVD)” dır (Organ 1988; Podsakoff 2000). ÖVD, Çalışanların örgütte çalışan diğer kişilere yardım etme niyeti veya vicdanlı olma ve örgütü destekleme gibi biçimsel rolünün ötesine geçen isteğe bağlı davranışları içermektedir (Organ 1983).

ÖVD ile ilgili olarak literatürde çok çeşitli tanımlar olmasına karşın bu çalışmalarda genel olarak işaret edilen davranışların birbirleri ile örtüştüğü görülmektedir. Örneğin Kidder çalışmasında ÖVD için iş tanımlarının dışında davranışların potansiyel sonuçları ve göstergelerine ilişkin olduğu ve ekstra rol davranışları konseptine dayandığını ifade etmektedir( Kidder 2002). O’Brien ise genel olarak örgütün performansı ve etkililiğini artırmak amacıyla çalışanların isteğe bağlı olarak sergiledikleri ve örgütün amaç ve misyonunu destekleme, örgüt çıkarlarını şahsi çıkarların üstünde tutma, örgüte yenilikler sunma gibi yapıcı davranışların ÖVD olarak değerlendirildiğini belirtmektedir (O'Brien 2008).

Dolayısıyla vatandaşlık davranışları yalnızca gönüllü olarak yapılan davranışlardır. Bunlar biçimsel iş gereklerinin bir parçası olmaktan çıkmaktadır. Örgüt içerisinde formel biçimde ödüllendirilen davranışlar çalışanların iş anlaşmalarında yer aldığından ÖVD'den farklı olarak görev gerekleri arasında yer almaktadır. Literatürde örgütsel vatandaşığın boyutlarına ilişkin birçok çalışma olmasına karşın araştırmacıların en çok referans gösterdiği Organ (1988) çalışmasında beş boyutu sıralamaktadır:
a. Vicdanlılık(Concientiousness)
b. Nezaket (Courtesy)
c. Diğergamlık (Altruism)
d. Centilmenlik (Sportsmenship)
e. Sivil Erdem(Civic Virtue)

Ancak geçici organizasyonlar; belirli ve çoğunlukla kısa bir zaman dilimi için varolması, takım çalışması odaklı olması ve belirli bir göreve odaklanmış olması bakımından kalıcı organizasyonlardan ayrışmaktadır (Bakker 2010; Katz 1982; Lundin 1995). Bu bakımdan literatüre önemli bir katkı olarak ÖVD’nin proje organizasyonuna uyarlanmasına ilişkin az sayıda çalışma bulunmaktadır (Braun 2013; Provan 2014). Bunlardan birisi olan Braun'un çalışması Tablo 2'de yansıtılmıştır. Ayrıca ÖVD davranışlarının boyutlarını inceleyerek proje, takım, grup, şebeke gibi geçici/farklı organizasyon konseptine uyarlayan diğer çalışmalar bulunmaktadır (Lee 2004; Autry 2008; Skinner 2009).

Tablo 2: Braun'un Örgütsel Vatandaşlık Davranışlarını Proje Vatandaşlığı Konseptine Uyarladığı Çalışma

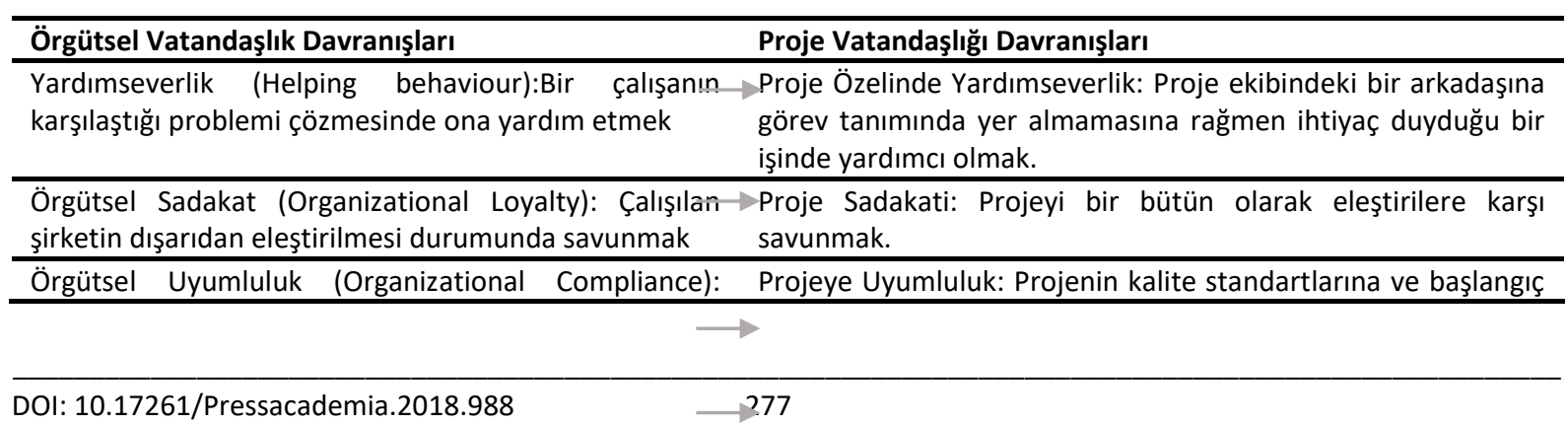




\begin{tabular}{lll}
\hline Kurumun kural ve politikalarına saygı duymak. & toplantısında belirlenen kurallara uymak \\
\hline $\begin{array}{l}\text { Kişisel inisiyatif (Individual Initiative):Organizasyonda } \\
\text { ek sorumluluklar almaya gönüllü olmak. }\end{array}$ & $\begin{array}{l}\text { Proje Özelinde Proaktif Davranışlar: Kontratta olmamasına } \\
\text { rağmen projede bilinçli ve gönüllü olarak minimum seviyenin } \\
\text { üzerinde performans göstermek. }\end{array}$ \\
\hline $\begin{array}{l}\text { Sivil erdem (Civic Virtue): Organizasyonun yönetişim } \\
\text { süreçlerine sorumlu, yapıcı katılım sağlamak. }\end{array}$ & $\begin{array}{l}\text { ilişki Yönetimi (Relationship maintenance): Projenin } \\
\text { kapanışından sonra bile proje paydaşları ile görüşmeye devam } \\
\text { etmek }\end{array}$ \\
\hline
\end{tabular}

Örgütsel vatandaşlık ve proje vatandaşlığı davranışlarının grup performansı, çalışanlar arası uyum, müşteri memnuniyeti, finansal performans, takımın genel performansına etkisine ilişkin ilişkin literatürde bir çok ampirik çalışma bulunmaktadır. Tablo 3'te bu çalışmalardan bir kısmı özetlenmiştir. Buna göre geçici organizasyonlarda vatandaşlık davranışları özellikle takım ve grup performansına olumlu etki etmekte olduğu bulgusuna rastlanmıştır (Podsakoff 1997; Cohen 2000; Bolino 2002).

Ayrıca vatandaşlık davranışları çalışanlar arasındaki koordinasyonun artmasını pozitif yönde etkilemektedir (Organ 1995). Örgütsel vatandaşlık davranışlarını yüksek oranda sergileyen çalışanlar müşterilerin beklentilerinin ötesinde davranışlarda bulunurlar ve bu durum müşteri memnuniyetinin artmasını sağlar (Morrison 1995; Walz 1996). Örgütün finansal performansı ile örgütsel vatandaşlık davranışlarının bulunma oranı arasında doğrusal ilişki olduğu sonucuna varılmıştır (Koys 2001). Projenin genel performansına ilişkin yapılan araştırmada proje vatandaşlığı davranışlarının projenin performansını pozitif yönde etkilediği bulgusuna ulaşılmıştır (Guo 2016). Dolayısıyla başarılı bir proje yönetimi için proje paydaşlarında proje vatandaşlığı davranışlarının sergilenmesi önem arz etmektedir.

Tablo 3: Örgütsel Vatandaşlık Davranışlarının Örgüte Etkisi

\begin{tabular}{|c|c|c|}
\hline Araştırmacı & Bulgu Detayı & Etki Boyutu \\
\hline $\begin{array}{l}\text { Podsakoff, } \\
\text { Cohen, } \\
\text { Bolino } 2002 .\end{array}$ & $\begin{array}{l}\text { Vatandaşlık davranışları özellikle takım ve grup performansına } \\
\text { olumlu etki etmektedir. }\end{array}$ & Grup performansı \\
\hline Organ, 1995. & $\begin{array}{l}\text { Vatandaşlık davranışları çalışanlar arasındaki koordinasyonun } \\
\text { artıasına olumlu etksi olmaktadır. }\end{array}$ & $\begin{array}{l}\text { Çalışanlar arası uyum- } \\
\text { koordinasyon }\end{array}$ \\
\hline $\begin{array}{l}\text { Morrison, } 1995 . \\
\text { Walz, Niehoff, } 1996 .\end{array}$ & $\begin{array}{l}\text { Örgütsel vatandaşlık davranışı yüksek çalışanlar müşteri } \\
\text { beklentilerinin ötesinde davranırlar ve müşteri memnuniyetini } \\
\text { pozitif etkiler. }\end{array}$ & Müşteri memnuniyeti \\
\hline Koys, 2001. & $\begin{array}{l}\text { Örgütsel vatandaşlık davranışları ile örgütün finansal performansı } \\
\text { arasında aynı yönlü ilişki vardır. }\end{array}$ & Finansal performans \\
\hline Guo, 2016 & $\begin{array}{l}\text { Proje vatandaşlığı davranışları projenin performansını olumlu } \\
\text { etkiler. }\end{array}$ & Proje performansı \\
\hline
\end{tabular}

\section{PROJEYE BAĞLILIK}

Örgütsel bağlılık, çalışanın işteki tecrübelerine ve organizasyona ilişkin algısına bağlı olarak organizasyona yönelik pozitif hislerini içermektedir ve organizasyon ile çalışan arasındaki ilişkide anahtar faktör olarak değerlendirilmektedir (Mowday, Porter \& Steers 1982). Örgütsel bağlılık, kişinin çalıştığı organizasyon ile psikolojik açıdan özdeşleşmesi ve o organizasyona ve amaçlarına bağlanma düzeyidir ve günlük olaylardan etkilenmez daha durağan bir yapıdadır (Güney 2011). Buna göre örgütsel bağlılık; çalışanların organizasyonun amaçlarını kabullenmede güçlü inançlara sahip olmalarını, örgüt adına beklenilenin ötesinde büyük çaba göstermelerini ve örgütteki üyeliklerini devam ettirmede kuvvetli arzu duymaları sonucunu doğurur (Mowday, Porter \& Steers 1982). 
Projelerin başarıyla tamamlanmasında projeye olan pozitif bağlılık önemli rol oynamaktadır. Literatürde örgütsel bağlılık üzerine çok sayıda araştırma bulunmakla birlikte çok sınırlı sayıda araştırmanın projeye bağlılığı incelediği görülmüştür. Meyer'in modelindeki örgütsel bağlııı boyutlarını (Meyer 1991) proje bağlılığı konseptine uyguladığımızda şu göstergeler çıkmaktadır:

a. Projenin amacını benimseme,

b. Projenin başarısı için olağanüstü çaba sarf etmek ve fedakârlıkta bulunmak,

c. Projede yer almaktan güçlü memnuniyet duymak ve proje ile özdeşleşebilmek.

Bu anlamda projeye bağlıık davranışlarının yüksek oranda sergilendiği proje organizasyonlarında proje ekibi üyeleri projenin başarılı olabilmesi için ellerinden geleni yapacak ve kendilerinden beklenenin ötesinde çaba sarf edeceklerdir. Projeye bağlılık davranışları; en üst düzey proje başarısı için proje paydaşlarını gerekli gönüllü eylemleri yapmaya, görev tanımlarında yer almayan işleri bile tereddütsüz bir biçimde yürütme eğilimine yönlendirecektir.

Tablo 4: Örgütsel Bağlılık Davranışlarının Örgüte Etkisi

\begin{tabular}{|c|c|c|}
\hline Araştırmacı & Bulgu Detayı & Etki Boyutu \\
\hline Ochieng \& Price, 2010. & $\begin{array}{l}\text { Tüm proje takım üyelerinin amaçlarının proje } \\
\text { amaçları ile tamamen uyum sağlayabildiği } \\
\text { durumlarda proje başarısının elde edildiğini } \\
\text { göstermektedir. }\end{array}$ & Projenin başarısı \\
\hline Yang, Yen, \& Chiang, 2012. & $\begin{array}{l}\text { Ekip üyeleirinin bağlılık düzeyi takımın } \\
\text { performansına etki eden önemli bir faktördür. }\end{array}$ & Takım performansı \\
\hline $\begin{array}{l}\text { Wiener ve Vardi, 1980. Meyer 1989, } 1998 . \\
\text { Hackett, } \quad 1994 . \quad \text { Balay, } 2000 . \\
\text { Stup, 2006. }\end{array}$ & $\begin{array}{l}\text { Örgütsel bağlılık iş performansı üzerinde pozitif } \\
\text { olarak etki etmektedir. }\end{array}$ & İş performansı \\
\hline $\begin{array}{l}\text { Chow, } \\
\text { Davies, Severy ve Taylor } 2001\end{array}$ & $\begin{array}{l}\text { İşgörenlerin örgütsel bağlılık düzeyleri çalışan başına } \\
\text { düşen ortalama üretim miktarını olumlu olarak } \\
\text { etkilemektedir. }\end{array}$ & Üretim Verimliliği \\
\hline
\end{tabular}

Tablo 4'te örgütsel bağlılık davranışlarının örgütün performansına etkisine ilişkin çalışmalardan bazıları özetlenmiştir. Buna göre Ochieng, yürüttükleri ampirik çalışmanın sonucunda tüm proje takım üyelerinin amaçlarının proje amaçları ile tamamen uyum sağlayabildiği durumlarda proje başarısının elde edildiği bulgusuna ulaşmışlardır (Ochieng 2010). Diğer bir çalışmada ekip üyelerinin bağlılık düzeyinin takımın performansına etki eden önemli bir faktör olduğu sonucu ortaya çıkmıştır (Yang 2012). Ayrıca örgütsel bağlıık ile iş performansı arasında pozitif yönlü ilişki bulunmaktadır (Wiener 1980; Meyer 1989; Hackett 1994; Balay 2000). Yine araştırmalar göstermektedir ki iş görenlerin örgütsel bağlılık düzeylerinin yüksekliği, çalışan başına ortalama üretim miktarını olumlu etkilemektedir (Chow 1994; Davies 2001). Dolayısıyla istenilen sonuçlara ulaşabilmek ve başarıyla projeyi tamamlayabilmek için proje yönetimi modelinde projeye bağlılık düzeyinin de önemli bir bileşen olarak yer alması gerekmektedir.

\section{5. ÖĞRENEN PROJE ORGANIZASYONU}

Günümüzün hızla değişen rekabetçi ortamı örgütleri kendilerini sürekli geliştiren ve değişime hızlı adapte olan yapıda olmayı zorunlu kılar. Peter Senge'nin 1990'da yayımlanan “Beşinci Disiplin” adlı kitabı ile birlikte öğrenen örgüt kavramı literatürde yer etmiştir. Senge, öğrenen örgüt için insanların gerçekten varmak istedikleri hedeflere ulaşmak için kapasitelerin sürekli arttırıldı̆̆ı, yeni fikirlerin desteklendiği, ortak isteklerin serbestçe tartışıldığı ve insanların sürekli olarak nasıl öğreneceklerini beraberce öğrendikleri organizasyon tanımını yapar (Senge 2016). Buna göre öğrenen örgütte şu beş disiplinin var olması gerekir:
a. Kişisel ustalık
b. Zihinsel modeller
c. Paylaşılan vizyon
d. Takım öğrenmesi
e. Sistem düşüncesi 
Öğrenen örgüt; kendi tecrübelerinden etkili olanları bularak örgüte uyarlayan ve bu süreçte öğrenmeyi gerçekleştiren ve kendini sürekli olarak dönüştürebilen örgütlerdir (McGill 1993, Pedler 1991). Dolayısıyla sürekli bilgi oluşturma, bilgileri bireysel seviyeden örgüt seviyesine çıkarabilme, bilgiyi davranışlarına yansıtarak ve örgütsel süreçlerde kullanarak çevreye uyum sağlayabilme, kolayca değişen ve gelişen yapıda olma, ortak bir vizyon etrafında bütünsel olarak amaca doğru ilerleyebilme öğrenen organizasyonun göstergelerindendir.

Tablo 5: Öğrenen Örgüt Organizasyonu Karakteristiklerinin Örgüte Etkisi

\begin{tabular}{|c|c|c|}
\hline Araştırmacı & Bulgu Detayı & Etki Boyutu \\
\hline Kiani, 2014 & $\begin{array}{l}\text { Öğrenen organizasyon karakteristikleri ile organizasyonel } \\
\text { etkililik arasında pozitif ilişki vardır. }\end{array}$ & Organizasyonel etkililik \\
\hline $\begin{array}{l}\text { Norashikin, } \\
\text { Pokharel, } 2015\end{array}$ & $\begin{array}{l}\text { Öğrenen organizasyon kültürü organizasyonel performans ve } \\
\text { inovasyonu ve uzun vadede organizasyonel başarıyı } \\
\text { doğrudan etkilemektedir. }\end{array}$ & $\begin{array}{l}\text { Organizasyonel } \\
\text { performans }\end{array}$ \\
\hline Kyoungshin, 2017 & $\begin{array}{l}\text { Öğrenen organizasyon bilgi performansına ve bilgi } \\
\text { performansı ise finansal performansa pozitif etki etmektedir. }\end{array}$ & $\begin{array}{l}\text { Bilgi performansı, } \\
\text { Finansal performans }\end{array}$ \\
\hline Kontoghiorghes, 2005 & $\begin{array}{l}\text { Öğrenen organizasyon karakteristikleri ile değişime adapte } \\
\text { olma, inovasyon ve organizasyonel performans arasında } \\
\text { güçlü ilişki bulunmaktadır. }\end{array}$ & $\begin{array}{l}\text { Değişime adapte olma, } \\
\text { inovasyon, } \\
\text { Organizasyonel } \\
\text { performans }\end{array}$ \\
\hline
\end{tabular}

Öğrenen organizasyonun örgüt performansına etkisine ilişkin çok sayıda araştırma bulunmaktadır. Bu araştırmalardan bazıları Tablo 5'te özetlenmiştir. Yapılan bir amprik araştırmada öğrenen organizasyon karakteristiklerinin varlığı ile organizasyonel etkililik arasında pozitif bir ilişki olduğu sonucuna varılmıştır (Kiani, 2014). Ayrıca öğrenen organizasyon kültürü, organizayonel performans ve inovasyon uzun vadede organizasyonel başarıyı olumlu yönde etkilemektedir (Norashikin 2016, Pokharel 2015). Öğrenen organizasyon ile bilgi üretim/paylaşım performansı arasında ve bilgi performansı ile finansal performans arasında pozitif ilişki vardır (Kim 2017). Bununla birlikte öğrenen organizasyon karakteristikleri değişime adapte olmayı kolaylaştırmaktadır, örgütsel performansı artırmaktadır (Kontoghiorghes 2005).

Öğrenen organizasyonun proje organizasyonu konseptinde incelenmesi ve proje performansına etkisine ilişkin araştırmalara ihtiyaç vardır. Ancak örgütsel performansa etkisine ilişkin söz konusu araştırmalar proje yönetim modelinde öğrenen örgüt karakteristiklerini oluşturacak ögelere yer verilmesi gerektiğini ortaya koymaktadır.

\section{6. ÖNERILEN MODEL VE TARTIŞMA}

Proje organizasyonunun performansını rol içi ve rol dışı davranışlar bir bütün olarak oluşturduğu için önerilen modelin iki ana kolunu bu davranışlar oluşturmaktadır. Şekil 1'de gösterildiği gibi bu iki ana davranışların bir bütün olarak proje organizasyonunda yer alması proje organizasyonunun performansını ortaya çıkaracaktır. Bu kısımda model detaylandırılmıştır:

\subsection{Proje Organizasyonunda Rol İçi Davranışlar}

Projenin hedeflenen amaçlarına ulaşması ve başarıyla tamamlanabilmesi için projenin tanımlanan aktivitelerinin gerçekleştirilmesi yani proje organizasyonundaki rol içi davranışların uygulanması gerekmektedir. Proje yönetiminde dünya genelinde yaygın olarak kabul gören araç ve teknikler "Project Management Institute" tarafından bir araya getirilerek PMBOK adı ile yayımlanmış ve proje yönetim pratisyenlerinin istifadesine sunulmuştur. Diğer bir yaygın kabul gören benzer metodoloji "PRINCE 2" adı yayımlanmıştır. PRINCE 2 illk olarak İngiltere'de kullanılmaya başlanmış ve zamanla dünyada kabul gören bir metodoloji halini almıştır. Bu metodolojiler projelerin yönetilebilir bölümlere ayrılması, uçtan uca kontrolün sağlanması, projenin amaçlarına ulaşılması için hangi aşamada hangi adımların atılması gerektiğine dair bir yol haritası sunmakta, proje yöneticilerinin ve proje ekibinin işlerini kolaylaştırmaktadır. On yıllardır kullanılmakta olan araç ve tekniklerin uygulanmasının projenin başarısında etkisi olacağı muhakkaktır. Rol içi davranışların ikinci boyutu ise görev tanımında yer alan davranışların sergilenmesidir. Bu davranışlar proje ekibi üyesinin rol tanımında yer alan işleri ve sözleşmesi gereği yerine getirmesi gereken aksiyonları içermektedir. Ancak önceki bölümlerde de değindiğimiz gibi proje organizasyonundaki rol içi davranışlar projenin hedeflerine ulaşması için dikkate alınması gereken iki ana birisini oluşturmaktadır. Zira sadece belirlenen aktivitelerin kabul görmüş araç ve teknikler uygulanarak tamamlanması projeyi başarıya götürmek için yeterli değildir. 
Şekil 1: Model Önerisi

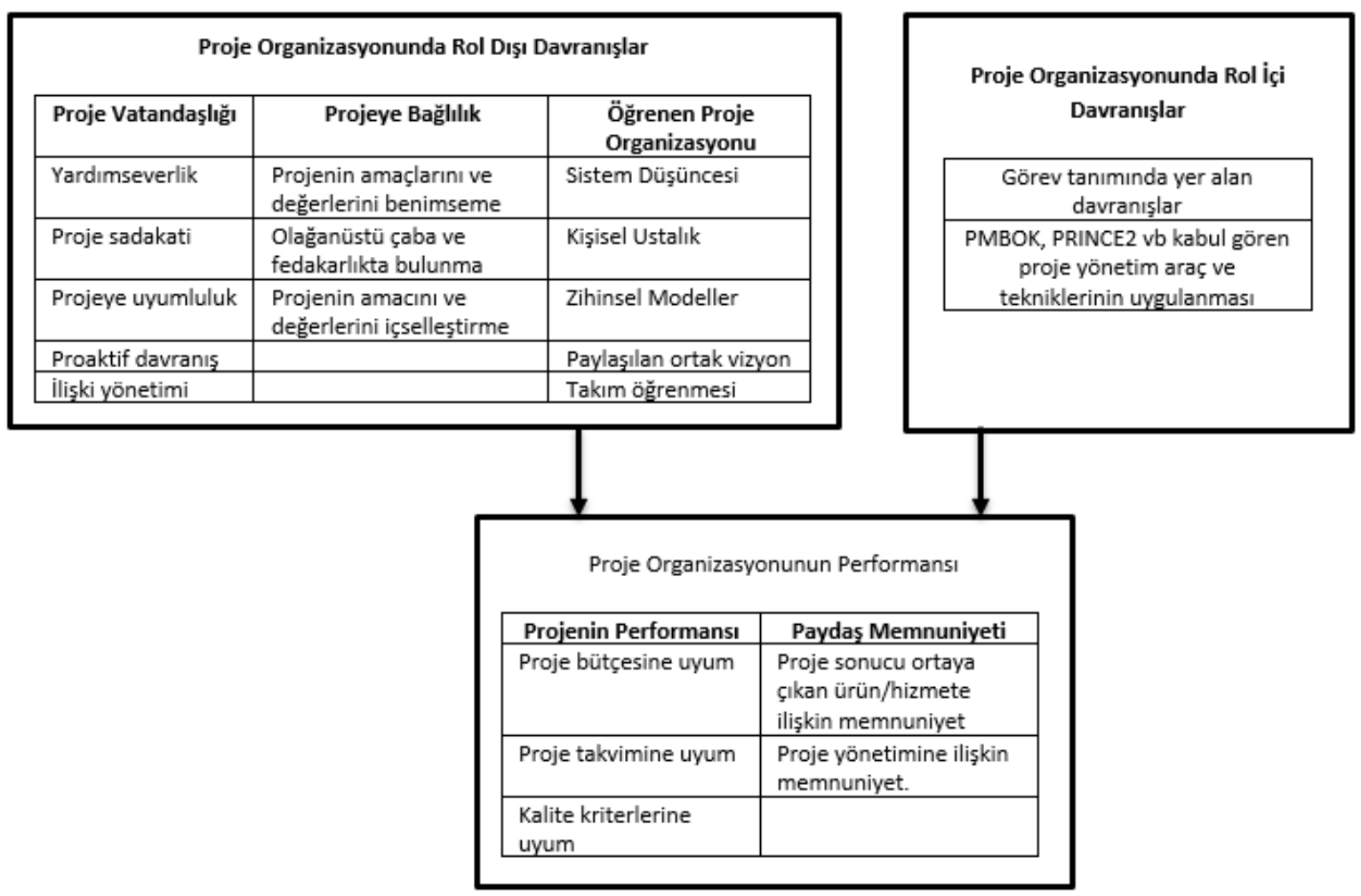

\subsection{Proje Organizasyonunda Rol Dışı Davranışlar}

Proje organizasyonunda bulunması gereken davranışların toplandığı ikinci ana kolu oluşturmaktadır. Bu çalışma ile önerilen modelin literatüre en önemli katkısı örgüt düzeyinde çokca incelenmiş olan "Örgütsel vatandaşlık, "Örgütsel bağlılık", "Öğrenen organizasyon" boyutlarının geçici bir organizasyon olarak "proje" ye uyarlanması ve bir bütün halinde model olarak proje yönetimi pratisyenlerinin ve akademisyenlerin istifadesine sunulmuş olmasıdır. Proje vatandaşlığının ilk boyutunu proje içerisinde "Yardımseverlik" davranışı oluşturmaktadır. Projelerin yürütülmesi aşamasında çeşitli nedenlerle proje ekibi üyeleri diğerlerinin yardımına ihtiyaç duyabilmektedir. Proje ekibinin kendi görev tanımlarında doğrudan yer almamasına rağmen proje vatandaşlığı davranışı sergileyip ekip olarak bir bütün olmanın gereğini sergileyerek gerekli yardımseverliği göstermesi proje için önemlidir. Yardımseverlik davranışı ekip üyelerinin informal ilişkilerinin gelişmesine, olumlu iklimin oluşmasına da katkıda bulunacaktır. Proje vatandaşlığının ikinci boyutu "Proje sadakati”dir. Projelerin geliştirilmesi genellikle bir yenilik getirmekle birlikte beraberinde bir değişimin gerçekleşmesi anlamına da gelmektedir. Bir çok organizasyonda değişim öncelikle tepkiyle karşılanır. Bu durumda proenin paydaşlarından bir kısmı projeye karşı direnç geliştirmesi beklenilir. Bu direnç çeşitli platformlarda projenin eleştirilmesini ve nihayetinde projeye ilişkin olumsuz fikirlerin yaygınlaşmasına neden olabilir. Özellikle bu tür durumlarda proje ekibinin projeye ilişkin sadakati projenin başarısına olan inancın ifade edilmesini gerektirir. Projeye ilişkin olumsuz havanın pozitife dönmesinde proje sadakati davranışı önemli rol oynayacaktır. "Projeye uyumluluk" proje vatandaşlığı davranışının diğer bir boyutudur. Her projenin başlangıcında projenin yürütülmesi aşamasında uyulması beklenilen bir takım kurallar ve kalite standartları belirlenir. Bu kurallar projenin başarıyla yürütülmesi için ortak bir zemin oluşmasını sağlamakta ve genellikle başlangıç toplantısında proje paydaşları ile paylaşılmaktadır. Böylelikle proje ekibi ortak bir zemin üzerinde kendilerine düşen aksiyonları tamamlar ve davranışları sergilerler. Proje paydaşlarının bir bütün olarak aynı hedefe doğru ilerlemesi için bu ortak kuralların benimsenmesi ve uyulması önem arzetmektedir ve proje vatandaşlı̆ının bir gereğidir. Diğer boyut ise "Proaktif davranışlar"dır. Projenin hedeflerine ulaşılması için tamamlanması gereken aksiyonların ve nasıl yapılacağının yüzde yüz olarak yazılı ifade edilmesi mümkün değildir. Bundan dolayı yazılı olmasa bile proje ekibi üyesinin kendisinden beklenilen aksiyonu tam anlamıyla yerine getirecek dvranışları sergilemesi projenin başarısı için elzemdir. Bu davranışlar yazılı olarak aksiyonun tanımında yer almayabilir, işe giriş sözleşmesinde bahsedilmiyor olabilir. Ancak sergilenmesi gereken davranışın ne olduğunu, hangi davranışın aksiyonun tamamlanmasını sağlayacağını en iyi ilgili proje ekibi üyesi bilebilir. Bu durumda proje yöneticisinin veya başka bir ekip üyesinin uyarısına gerek kalmadan ilgili proaktif davranışı sergileyerek proje işlerinin bir parçası olan aksiyonu tamamlaması gerekmektedir. Son olarak ilişki yönetimi proje vatandaşlığı boyutlarından 
birisidir. Kabul edilen tanımın aksine proje sadece başlangıç, planlama, yürütüme, kontrol ve kapanış aktivitelerinin tamamlanması akabinde amaçlanan ürünün veya hizmetin geliştirilmesinden ibaret değildir. Zira projenin kapanışı akabinde elde edilen sonuçlar proje paydaşlarını etkilemeye devam etmektedir. Proje vatandaşlığı davranışı kapanıştan sonra da proje paydaşları ile etkili iletişime devam etmeyi gerektirmektedir. Böylelikle sözkonusu proje içerisinde yer aldığı organizasyona, işletmeye maksimum düzeyde ve sürdürülebilir faydayı sağlamaya devam edecektir.

Modeldeki rol dışı davranış kategorilerinden ikincisini geliştirilen "Projeye bağlıık" kavramı oluşturmaktadır. Projeye bağlılık davranışı söz gelimi proje sponsorundan proje test mühendisine kadar proje paydaşlarından her birinin öncelikle projenin amaçlarını ve değerlerini benimsemesini gerektirir. Bunun için projenin amaçlarının ve değerlerinin proje sponsoru veya proje yöneticisi tarafından projenin başlangıç aktivitelerinden birisi olarak projenin paydaşları ile birlikte geliştirilmesi ve yine proje paydaşları ile uygun bir platformda paylaşılması gerekmektedir. İkinci boyutu üstün çaba ve fedakarlıkta bulunma davranışı oluşturmaktadır. Sadece tanımlı aksiyonların yine tanımlanan araç ve yöntemlerin uygulanması ile projede hedeflenen çıktılara ulaşılması mümkün değildir. Her aksiyon bir nebze de olsa tamamlamak için çaba sarfetmeyi ve belli ölçüde fedakarlıkta bulunmayı gerektirir. Projeye bağlı olan, projenin amaçlarını ve değerlerini benimseyen paydaşlar kendi görev tanımlarında yer almasa dahi bu çabayı ve fedakarlığı gerektiğinde sergilemeleri durumunda başarıya ulaşmak mümkün olabilecektir. Son olarak projenin amacını ve değerlerini içselleştirme projeye bağııık boyutlarından birisidir. Bahsi geçen içselleştirme çalışanın varmak istediği kişisel hedefleri ve kişisel değerleri ile projenin hedefleri ve değerlerinin uyumluluğuna ilişkindir. Bu davranışları sergileyen proje paydaşları proje organizasyonunun bir üyesi olmaktan gurur duyar ve projenin başarısı ile kişisel başarı hedefleri örtüştüğü için kendine düşenleri görev tanımında yer almasa bile yerine getirecek ve neticede projeye bağlılık davranışı sergileyen proje üyeleri ayrıca bir kontrol ve denetime gerek kalmaksızın proje için aksiyon alacaklardır.

Modelin rol dışı davranışlar kısmının üçüncü kategorisi öğrenen örgüt kavramından ilham ile geliştirdiğimiz "Öğrenen proje organizasyonu" dur. "Sistem düşüncesi" öğrenen proje organizasyonunun temel boyutlarından birisidir. Proje yönetimi doğası gereği bir çok proje paydaşının bir araya gelerek belirli bölümlere ayrılmış olan iş paketlerinden kendilerine atananları tamamlamalarını gerektirmektedir. Ancak bu bölümleme projeyi yürütmeyi kolaylaştırırken paydaşların projeyi bir bütün olarak görmesine mani olabilmekte, varılmak istenen asıl hedeften ziyade tali ve bireyselde kalan hedeflere odaklanmaya neden olabilmektedir. Bu durum bir süre sonra asıl hedefleri görmeyi unutturur. Oysaki projenin başarıyla tamamlanabilmesi birbiriyle ilişkili olan aksiyonların uyum içerisinde gerçekleştirilmesi, elde edilmek istenen asıl sonuçlara doğru ilerleyişin sürekli olarak gözlemlenmesi ile mümkündür. Sistem düşüncesi öğrenen proje organizasyonunda proje paydaşlarının kendilerine düşen iş parçalarını büyük sistemi oluşturan bir alt sistem olarak görmelerini sağlar ve büyük sistemden kopuşun önünü keser. Kişisel ustalık, Peter Senge tarafından kişisel yetişme ve öğrenme disiplini için kullanılmaktadır. Buna göre kişisel ustalık düzeyinde olan kişiler hayattaki ulaşmak istedikleri sonuçlara varma yeteneklerini sürekli genişletmektedirler. Böylelikle sürekli öğrenen organizasyon ruhu ortaya çıkar: bireyden örgüte... Proje organizasyonunun öğrenen organizasyon olması için paydaşların bireysel olarak kişisel ustalık düzeyine ulaşma bilincinde olması, bireysel öğrenme aşamalarını önemsemesi, yanlışlardan dersler çıkarıp diğerleri ile paylaşarak öğrenmenin bireysel düzeyden proje organizasyonu düzeyine ulaşmasını sağlaması gerekmektedir. Bu düzeydeki insanlardan oluşan ekip muhakkak ki başarıya daha yakındır. İkinci olarak zihinsel modeller kavramı öğrenen proje organizasyonu boyutlarından biri olarak öne çıkmaktadır. Proje paydaşlarının sahip olduğu zihinsel modeller projenin başarısına etki etmektedir. Proje organizasyonunda çeşitli etkenlerle kendiliğinden gelişen zihinsel modellerin yönlendirilerek projeye ilişkin olumlu iklimi yansıtan, pozitif etki uyandıracak faktörlerden oluşmasını sağlamak önemlidir. Projenin başarılı olmayacağına inanan bir ekibin projeyi başarıya ulaştırması mümkün değildir. Dördüncü boyut "paylaşılan ortak vizyon" varılmak istenilen şeye tekabul eder. Neyi elde etmek istiyorsak odur aslında. Öğrenen proje organizasyonu için önemli olan ise proje paydaşlarının tamamının elde etmek istediğinin, varmak istediği noktanın ortak olmasıdır. Hedef birliği risk almayı ve denemeyi kolaylaştırır. Birlikte dert etmenin sağlayacağı etki ile hedeflere kolaylıkla varılabilir, projenin başarı ile tamamlanması mümkün olabilir. Son olarak "takım öğrenmesi" önerilen modelde proje organizasyonunun başarıya ulaşması için olmazsa olmazlarından birisidir. Bireysel düzeyde kalan kişisel ustalık, olumlu zihinsel model ve kişisel vizyonun proje organizasyonuna pek bir faydası olmayacaktır. Öğrenmenin takım düzeyin eçıkması, proje paydaşlarının arzuladıkları sonuca ulaşabilme potansiyellerini geliştirecektir.

\subsection{Proje Organizasyonunun Performansı}

Proje organizasyonunda rol içi davranışların ve rol dışı davranışların birlikte bütün olarak sergilenmesi sayesinde çıktı olarak proje organizasyonunun performansı oluşacaktır. Bu kısım modelin üçüncü bölümünü oluşturmaktadır. Buna göre modelde öngörülen davranışların sergilenmesi projenin paydaşlar tarafından mutabık kalınan bütçesine uyum içerisinde tamamlanması, yine paydaşlar tarafından belirlenen takvime uygun olarak bitirilmesi ve ortaya çıkan ürün/hizmetin kalite kriterlerinin tam olarak karşılamasında rol oynayacaktır. Bunun yanında özellikle çalışmanın ikinci bölümünde işlendiği gibi projede paydaş memnuniyetinin sağlanması da başarı koşullarından birisidir ve proje organizasyonunun performansına dahildir. Buna göre proje sonucu ortaya çıkarn ürün/hizmete ilişkin paydaşların memnuniyeti ve proje yönetimine ilişkin memnuniyetin maksimum düzeye erişmesi modelde izah edilen rol içi ve rol dışı davranışların sergilenmesiyle mümkün olacaktır. 


\section{SONUÇ}

Proje yönetimi stratejik bir yönetim aracı olarak günümüzde organizasyonların çoğunda ürün veya hizmet üretme amaçlı olarak başvurulmaktadır. Araştırmalar proje yönetiminde insan faktörünü, katılımcılığı ve öğrenmeyi önceleyen esnek paradigmanın (soft paradigm); araçlar, teknikler, önceden belirlenen hedeflere ulaşmak için sürekli kontrolü önceleyen katı paradigmaya (hard paradigm) göre artan bir şekilde kabul gördüğünü göstermektedir. Sistem düşüncesine dayanan ve esnek (soft) paradigmadan beslenen alternatif modellerin geliştirilmesine ihtiyaç bulunduğu görülmektedir. Bu çalışma ile geliştirilen model, proje yönetiminde esnek paradigmayı benimseyen akademisyenler, proje yönetimi profesyonelleri ve yöneticilerin istifadesi için başarıyı maksimize etmeye götürecek olan rol dışı davranışlara dayalı faktörleri bir araya getirmektedir. Modelin genişletilmesi ve bütünsel olarak doğrulanması bundan sonraki araştırmaların konusu olacaktır.

\section{KAYNAKÇA}

Akerlof, G. A. (1970). The market for "Lemons": quality uncertainty and the market mechanism. Quarterly Journal of Economics, vol. 84, no. 3, pp. 488-500.

Alessandri, T., Cerrato, D., Depperu, D. (2014). Organizational slack, experience, and acquisition behavior across varying economic environments. Management Decision, vol. 56, no. 5, pp. 967-982.

Atkinson, R. (1999). Project management: cost, time and quality, two best guesses and a phenomenon, its time to accept other success criteria. International Journal of Project Management, 17-6, 337-342.

Autry, C. W., Skinner, L. R., Lamb, C. W. (2008). Intraorganizational citizenship behaviors: an empirical study. Journal of Business Logistics, 29, $53-74$.

Baccarini, D. (1999). The logical framework method for defining project success. Project Management Journal, 30 (4):25-32

Barnard, C. (1938). The functions of the executives. Harvard University Press, Boston.

Balay, R. (2000). Yönetici ve öğretmenlerde örgütsel bağlılık. Nobel Yayın Dağıtım, Ankara.

Baker, B. N. Murphy, D. C., Fisher, D. (1983). Factors affecting project success. Project management handbook. New York: Van Nostrand Reinhold.

Bakker, R. M., (2010). Taking stock of temporary organizational forms: a systematic review and research agenda. International Journal of Management Reviews 12, 466-486.

Bolino, M. C., Turnley, W. H., Bloodgood, J. M. (2002). Citizenship behavior and the creation of social capital in organizations. Academy of Management Review, 27, 505-522.

Braun, T., Ferreira A. I., Sydow J. (2013). Citizenship behavior and effectiveness in temporary organizations. International Journal of Project Management 31, 862-876.

Chow, I. H. (1994). Organizational commitment and career development of Chinese managers in Hong Kong and Taiwan. International Journal of Career Management, 6, 4, 3-9.

Cohen, A., Vigoda, E. (2000). Do good citizen make good organizational citizenship: an empirical examination of the relationship between general citizenship and organizational citizenship. Administration and Society, 32, 5, 596-625.

Davies, D., Taylor, R., Savery, C. (2001). The role of appraisal, remuneration and training in improving staff relations in the Western Australian accommodation industry: a comparative study. Journal of European Industrial Training, 25, 366-373. http://dx.doi.org/10.1108/EUM0000000005837.

Drago, R., Garvey, G. (1998). Incentives for helping on the job: theory and evidence. Journal of Labor Economics, 1-25.

Guo, S., Wang, X., Li, M. (2016). Citizenship behaviour and performance in a project management context. Construction Research Congress 2016, ASCE.

Gülesin, Z., Gürol Y. (2016). Proje yönetiminde paradigm değişimi: katı yönetim yaklaşımından yumuşak yönetim yaklaşımına geçiş. Yönetim Bilimleri Sempozyumu, i̇stanbul.

Gülesin, Z., Can, E. (2015). A theoretical overview on challenges and solutions for global project management. Research Journal of Business and Management 2, 3.

Güney, S. (2011). Örgütsel davranış. Nobel Dağııım, pp:32-33.

Hackett, R. D., Bycio, P., Hausdorf, P. A. (1994). Further assessments of Meyer and Allen's (1991) three- component model of organizational commitment. Journal of Applied Psychology, 79,1, 1-9. 
Ika, L. A. (2015). Opening the black box of project management: does World Bank project supervision influence project impact?. International Journal of Project Management, 33, 5, 1111-1123.

Katz, R. (1982). The effects of group longevity on project communication and performance. Administrative Science Quarterly 27, 81-104.

Khang, D. B., Moe, T. L. (2008). Success criteria and factors for international development projects: a life cycle based framework. Project Management Journal, 39 ,1, 72-84.

Keskin, H., Akgün, A., Koçoğlu, i. (2016). Örgüt teorisi. Nobel Dağıtım, 153-154.

Kerzner, H. (1998). In search of excellence in project management. Wiley, New York.

Kiani, M. N., Gillani S. H. M. (2014). The impact of learning organization practices on organizational effectiveness. Pakistan Business Review, 16, 2 .

Kidder, D. L. (2002). The influence of gender on the performance of organizational citizenship behvaviours. Journal of Management, $28,5,629$ 648.

Kim, K., Watkins, K. E., Lu, Z. L. (2017). The impact of learning organization on performance: focusing on knowledge performance and financial performance. European Journal of Training and Development, 41-2, 177-193.

Kontoghiorghes, C., Awbre, S. M., Feuring, P. L. (2005). Examining the relationship between learning organization characteristics and change adaptation, innovation, and organizational performance. Human Resource Development Quarterly, 16-2.

Koys, D. J. (2001). Effects of employee satisfaction, organizational citizenship behavior, and turnover on organizational effectiveness: a unitlevel, longitudinal study. Personnel Psychology, S.54, s.101-114.

Lee, D.-J., Sirgy, M. J., Brown, J. R., Bird, M. M. (2004). Importers' benevolence toward their foreign export suppliers. Journal of the Academy of Marketing Science, 32, 32-48.

Leblebici, D. N. (2008). Örgüt kuramında paradigmalar ve metaforlar. Selçuk Üniversitesi İtisadi ve İdari Bilimler Fakültesi Sosyal ve Ekonomik Araştırmalar Dergisi, 8 (15), 245-360.

Lundin, R. A., Söderholm, A. (1995). A theory of the temporary organization. Scandinavian Journal of Management, 11, 437-455.

McGill, M. E., Slocum, J. W. (1993). Unlearning the organization. Organizational Dynamics, 22,2, 68-73.

Meyer, J. P., Paunonen, S. V., Gellatly, I. R., Goff, R. D., Jackson, D. N. (1989). Organizational commitment and job performance: it’s the nature of the commitment that counts. Journal of Applied Psychology, 74 (1): 152-6.

Meyer, J. P., Allen, N. J. (1991). A three-component conceptualization of organizational commitment. Human Resource Management Review 1 (1): 61-89.

Morrison, E. W. (1995). Organizational citizenship behavior as a critical link between HRM practices and service quality. Human Resource Management, S.35, s.493-512.

Mowday, R. T., Porter, L. W., Steers, R. M. (1982). Employee organization linkages: the pyschology of commitment, absenteeism and turnover. Academic Press, London.

Netemeyer, R. G., Maxham, J. G. (2007). Employee versus supervisor ratings of performance in the retail customer service sector differences in predictive validity for customer outcomes. Journal of Retailing, 83, 131-145.

Norashikin, H., Omar, S., Noordin, F., Ishak, N. A. (2014). Learning organization culture, organizational performance and organizational innovativeness in a public institution of higher education in Malaysia: a preliminary study. Procedia Economics and Finance, 37, 512-519.

O'Brien, K. E., Allen, T. D. (2008). The relative importance of correlates of organizational citizenship behaviour and counterproductive work behaviour using multiple sources of data. Human Performance, 21, 62-88.

Organ, D., Smith, C. A., Near, P. J. (1983). Organizational citizenship behavior: its nature \& antecedents. Journal of Applied Psychology, 68(4):653:663.

Organ, D. (1988). Organizational citizenship behaviour: the good soldier syndrome. Lexington, MA: Lexington Books.

Organ, D. W., Ryan, K. (1995). A meta-analytic review of attitudinal and dispositional predictors of organizational citizenship behavior. Personnel Psychology, S.48, S.775-802.

Pedler, M., Burgoyne, J., Boydell, T. The learning company: a strategy for sustainable development. McGraw-Hill Book, London.

Podsakoff, P. M., MacKenzie, S., Paine, J., Bachrach, D. (2000). Organizational citizenship behaviors: a critical review of the theoretical and empirical literature and suggestions for future research. Journal of Management, 26 (3), 513-563.

Podsakoff, P. M., \& MacKenzie, S. B. (1997). Impact of organizational citizenship behavior on organizational performance: a review and suggestions for future research. Human Performance, 10, 133-151. 
Pokharel, P. M., Choi, S. O. (2015). Exploring the relationships between the learning organization and organizational performance. Management Research Review, 38, 2, 126-148.

Project Management Institute (PMI). (2013). A guide to the project management body of knowledge- Fifth edition. Newtown Square.

Pinto, J. K., Prescott J. E. (1990). Planning and tactical factors in the project implementation process. Journal of Management Studies, 27, 305327.

Senge, P. (2016). Beşinci disiplin. Yapı Kredi Yayınları, İstanbul.

Selznick, P. (1948). Foundations of the theory of organization. American Sociological Review, 13(1), 1948, 38-55.

Skinner, L. R., Autry, C. W., Lamb, C. W. (2009). Some measures of interorganizational citizenship behaviors: scale development and validation. International Journal of Logistics Management, 20, 228-242.

Provan, G. K., Sydow, J. (2014). Network citizenship behaviour: toward a behavioral perspective on multi-organizational networks. Academy of Management Annual Meeting Proceedings, DOI: 10.5465/AMBPP.2014.11520abstract.

Ochieng, E., Price, A. D. F. (2010). Managing cross-cultural communication in multicultural construction project teams: the case of Kenya and UK. International Journal of Project Management, 28, 449-460.

Turner, J. R. (1999). The project management profession: knowledge or faith?. PM Network, 13(10), 41.

Walz, S. M., Niehoff, B. P. (1996). Organizational citizenship behaviors and their effect on organizational effectiveness in limited-menu restaurants. Academy of Management Best Paper Proceedings, s.307-311.

Westerveld, E. (2003). The project excellence model: linking success criteria and critical success factors. International Journal of Project Management, 21, $411-418$.

Wiener, Y., Vardi, Y. (1980). Relationships between job, organization, and career commitments and work outcomes - an integrative approach. Organizational Behavior and Human Performance, 26, 81-96.

Yang, L., Chiang, Y., Yen, H. (2012). A framework for assessing impacts of leadership competency on police project performance: mediating role of job satisfaction and moderation role of project type. Policing: An International Journal of Police Strategies Management, 35 ,3, $528-550$.

Zinn, J. (2007). Use soft skills to solve hard challenges. Material Handling Management, 56. 